УДК 538.9

\title{
Electromechanical Properties and Anisotropy of Acoustic Waves Characteristics in Single Crystals $\mathrm{YAl}_{3}\left(\mathrm{BO}_{3}\right)_{4}$
}

\author{
Pavel P. Turchin* \\ Institute of Engineering Physics and Radioelectronics, \\ Siberian Federal University, \\ Svobodny, 79, Krasnoyarsk, 660041 \\ Kirensky Institute of Physics \\ Federal Research Center KSC SB RAS \\ Akademgorodok, 50/38, Krasnoyarsk, 660036 \\ Russia \\ Sergey I. Burkov \\ Vladimir I. Turchin \\ Sergey V. Yurkevich \\ Pavel O.Sukhodaev \\ Irina S. Raikova \\ Institute of Engineering Physics and Radioelectronics \\ Siberian Federal University \\ Svobodny, 79, Krasnoyarsk, 660041 \\ Russia
}

Received 09.08.2019, received in revised form 16.09.2019, accepted 06.10.2019

Velocity of bulk acoustic waves in base and rotated cuts have been measured by the ultrasonic pulse-echo method and values of $C_{i j k l}^{E}$ and $e_{i j k}$ in single crystals $\mathrm{YAl}_{3}\left(\mathrm{BO}_{3}\right)_{4}$ have been calculated. The value of $d_{i j k}$ piezoelectric modulus of these single crystals have been determined by quasistatic measurements, and $\varepsilon_{i j}^{\sigma}$ dielectric constants have been determined by the flat capacitor method. Experimental values of material constants have been applied for the study of anisotropy of acoustic waves characteristics in single crystals $\mathrm{YAl}_{3}\left(\mathrm{BO}_{3}\right)_{4}$.

Keywords: electromechanical properties, acoustic waves, multiferroics.

DOI: 10.17516/1997-1397-2019-12-6-756-771.

\section{Introduction}

Globally, a lot of attention is paid to the study of multiferroics [1-3], which include trigonal rare-earth oxyborates $\mathrm{RMe}_{3}\left(\mathrm{BO}_{3}\right)_{4}$ (where $\mathrm{R}=\mathrm{Y}$, La-Lu; Me $=\mathrm{Fe}$, Al, Cr, Ga, Sc). Ferroborates $\left(\mathrm{RFe}_{3}\left(\mathrm{BO}_{3}\right)_{4}\right)[4-6]$ are characterized by giant magnetoelectric [7] and magnetodielectric [8] effects. Alumoborates $\mathrm{RAl}_{3}\left(\mathrm{BO}_{3}\right)_{4}$ that combine good luminescent properties and are a promising material for laser technology [9-11] are also of interest for practical applications, and single crystal $\mathrm{YAl}_{3}\left(\mathrm{BO}_{3}\right)_{4}$ is used as a fourth harmonic generator in Nd:YAG laser [12]. Yttrium alumoborate $\mathrm{YAl}_{3}\left(\mathrm{BO}_{3}\right)_{4}$ in the oxyborate series is a nonmagnetic single crystal and can characterize the anisotropy of the elastic-electric interaction in them. There are well-known cases of studying electromechanical properties of oxyborates [13-15], but no such studies have been carried out for yttrium alumoborate.

To study electromechanical properties of single crystals $\mathrm{YAl}_{3}\left(\mathrm{BO}_{3}\right)_{4}$, the ultrasonic pulseecho method $[16,17]$ which allows to determine the velocities of bulk acoustic waves (BAW) with

*pturchin@sfu-kras.ru

(c) Siberian Federal University. All rights reserved 
the accuracy of no worse than $10^{-4}$, was used. The point group of $\mathrm{YAl}_{3}\left(\mathrm{BO}_{3}\right)_{4}$ single crystals $\mathrm{YAl}_{3}\left(\mathrm{BO}_{3}\right)_{4}$ symmetry is the same as in $\mathrm{La}_{3} \mathrm{Ga}_{5} \mathrm{SiO}_{14}$ (langasite) 32 (spatial symmetry groups R32 and P321, respectively). Therefore, the choice of the directions for BAW propagation and cuts to determine elastic, piezoelectric and dielectric properties in the single crystals under study correlate with studies $[18,19]$, where the values of linear electromechanical constants of langasite were found. In contrast to $[18,19]$, instead of rotated 45-degree cuts, close to it crystallographic

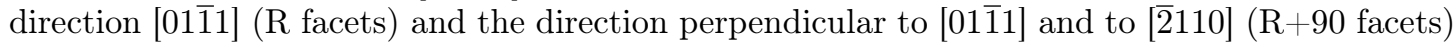
are used in this work.

In addition to pulse-echo measurements of BAW velocities and determination of the values of elastic $\mathrm{C}_{i j k l}^{E}$ and piezoelectric $\mathrm{e}_{i j k}$ constants on their basis, quasi-static $[20,21]$ studies of piezoelectric moduli $\mathrm{d}_{i j k}$, which are related to $\mathrm{e}_{i j k}$ ratio [22] were carried out

$$
e_{i j k}=d_{i l m} C_{l m j k}^{E} \text {. }
$$

To eliminate ambiguity in the signs of piezoelectric constants, direct measurements of the direction of electric polarization of the samples in the direction of the polar axis of the crystal were carried out. All the measurements were performed in the crystal physical coordinate system, where $\mathrm{C}_{14}<0$ [23]. The low-frequency values of dielectric constant $\varepsilon_{11}^{\sigma}$ of single crystals $\mathrm{YAl}_{3}\left(\mathrm{BO}_{3}\right)_{4}$ were determined using the flat capacitor method.

The obtained values of electromechanical constants of single crystals made it possible to analyze the anisotropy of the main characteristics of BAW and surface acoustic waves (SAW). These data make it possible to form an opinion about the magnitude of the elastic-electric interaction for the longitudinal and shear strains in various directions of the crystals under study.

\section{Theory}

Propagation of BAW in acentric nonmagnetic single crystals is described by the GreenChristoffel equations [23, 24]

$$
\left(\Gamma_{i l}-\lambda \delta_{i l}\right) U_{l}=0
$$

where the following notations are used: $\Gamma_{i l}=C_{i j k l}^{E} n_{i} n_{j}+\frac{e_{i} e_{l}}{\varepsilon^{*}}-$ the Christoffel symmetric tensor for piezoelectrics, $\lambda_{i}=\rho v^{2}$ - eigenvalues of $\Gamma_{i l}, \delta_{i l}$ - the Kronecker tensor, $U_{l}-$ eigenvectors of $\Gamma_{i l}, e_{l}=e_{p l m} n_{p} n_{m}$ and $e_{i}=e_{n i k} n_{n} n_{k}-$ piezoelectric vectors, $\varepsilon^{*}=\varepsilon_{r s}^{\eta} n_{r} n_{s}$ the convolution of the high-frequency dielectric constant, $n_{i}$ - the unit vector of wave normal.

The orientations of the crystal physical directions used to determine the electromechanical constants are given in Fig. 1. Solutions of equations (2) for directions perpendicular to $x, y$, and z-cuts (crystal-physics directions [100], [010] and [001] respectively) and rotated cuts $\mathrm{R}$ $([0 \cos \varphi \sin \varphi])$ and $\mathrm{R}+90([0-\sin \varphi \cos \varphi])\left(\varphi=48.05^{\circ}\right)$ are presented in Tab. 1 and Tab. 2.

Abundant number of solutions for non-piezoelectric active BAW given in Tab. 1 and 2 provides the necessary and verification relations for determining the elastic constants $\mathrm{C}_{i j k l}$. Piezoelectric active modes also allow determining the absolute values and the mutual sign of piezoelectric constants $\mathrm{e}_{11}$ and $\mathrm{e}_{14}$.

The values of $\mathrm{e}_{11}$ and $\mathrm{e}_{14}$ and their sign can also be determined from the equation (1) if $\mathrm{C}_{i j k l}^{E}$ and piezoelectric modulus $\mathrm{d}_{i j k}$, which are given by the equation of state (3) [22,23] are known

$$
D_{i}=d_{i j k} \sigma_{j k},
$$

where $D_{i}$ is electric induction; $\sigma_{j k}$ is mechanical stress tensor. 


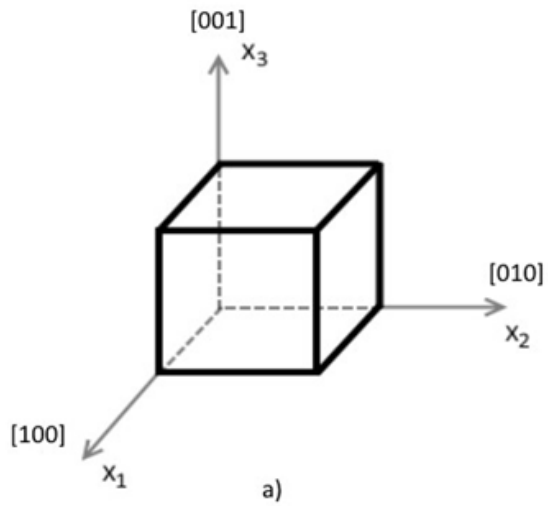

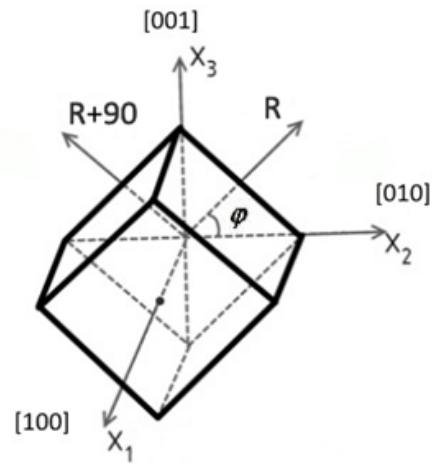

6)

Fig. 1. Crystal physical orientation of directions and cuts. a) basic $x, y, z$ - cuts; b) rotated $R$ and $\mathrm{R}+90$ cuts

Table 1. Relations between BAW velocities and linear material constants in crystals of symmetry 32 for base cuts

\begin{tabular}{|c|c|c|c|c|c|}
\hline № & $\lambda_{i}=\rho v_{i}^{2}$ & $\vec{n}$ & $\vec{U}$ & Mode & Relations with material constants \\
\hline 1 & $\lambda_{1}$ & {$[001]$} & {$[001]$} & $\mathrm{L}$ & $C_{33}$ \\
\hline 2 & $\lambda_{2}$ & & & $\mathrm{~S}$ & $C_{44}$ \\
\hline 3 & $\lambda_{3}$ & {$[100]$} & {$[001]$} & $\mathrm{L}$ & $\mathrm{C}_{11}+\frac{e_{11}^{2}}{\varepsilon_{11}^{\eta}}$ \\
\hline 4 & $\lambda_{4}$ & & & $\mathrm{~S}$ & $\frac{1}{2}\left(\mathrm{C}_{66}+\mathrm{C}_{44}\right)+\frac{1}{2} \sqrt{\left(C_{66}-C_{44}\right)^{2}+4 C_{14}^{2}}$ \\
\hline 5 & $\lambda_{5}$ & & & $\mathrm{~S}$ & $\frac{1}{2}\left(\mathrm{C}_{66}+\mathrm{C}_{44}\right)-\frac{1}{2} \sqrt{\left(C_{66}-C_{44}\right)^{2}+4 C_{14}^{2}}$ \\
\hline 6 & $\lambda_{6}$ & {$[010]$} & {$[100]$} & $\mathrm{L}$ & $\mathrm{C}_{66}+\frac{e_{11}^{2}}{\varepsilon_{11}^{\eta}}$ \\
\hline 7 & $\lambda_{7}$ & & & $\mathrm{~S}$ & $\frac{1}{2}\left(\mathrm{C}_{44}+\mathrm{C}_{11}\right)+\frac{1}{2} \sqrt{\left(C_{11}-C_{44}\right)^{2}+4 C_{14}^{2}}$ \\
\hline 8 & $\lambda_{8}$ & & & $\mathrm{~S}$ & $\frac{1}{2}\left(\mathrm{C}_{44}+\mathrm{C}_{11}\right)-\frac{1}{2} \sqrt{\left(C_{11}-C_{44}\right)^{2}+4 C_{14}^{2}}$ \\
\hline
\end{tabular}

\section{Experiment}

The block diagram of the ultrasonic pulse-echo method [17] is presented in Fig. 2.

In this method, a nanosecond pulse from generator 1 is transmitted to the piezoelectric transducer 3 and, after repeated reflection in sample 4, a series of reflected pulses is recorded by the oscilloscope 6 . The wideband signal limiting amplifier 2, limits the amplitude of the probe pulse to the input voltage level of the oscilloscope 6 and increases sensitivity of the method when recording small amplitude signals. The rubidium frequency standard 7 provides temperature stabilization of the oscilloscope clock frequency 6 . The master oscillator 5 synchronizes the start of the oscillator 1 and the sweep of oscilloscope 6 . The experimental value of the bulk acoustic wave velocity in the implemented method is found from the known sample length 1 and the measured pulse propagation time in the sample $\tau-v=\frac{2 l}{\tau}$. An example of a recorded series 
Table 2. Relations between BAW velocities and linear material constants in crystals of symmetry 32 for rotated $\mathrm{R}$ and $\mathrm{R}+90$ cuts $\left(\varphi=48.05^{\circ}\right)$

\begin{tabular}{|c|c|c|c|c|c|}
\hline № & $\lambda_{i}=\rho v_{i}^{2}$ & $\vec{n}$ & $\vec{U}$ & Mode & Relations with material constants \\
\hline 1 & $\lambda_{9}$ & {$[0 \cos \varphi \sin \varphi]$} & [100] & $\mathrm{S}$ & $\begin{array}{c}C_{66} \cos ^{2} \varphi+C_{44} \sin ^{2} \varphi+ \\
+2 C_{14} \cos \varphi \sin \varphi+ \\
+\frac{\left(e_{11} \cos ^{2} \varphi+e_{14} \cos \varphi \sin \varphi\right)^{2}}{\varepsilon_{11}^{\eta} \cos ^{2} \varphi+\varepsilon_{33}^{\eta} \sin ^{2} \varphi}\end{array}$ \\
\hline 2 & $\lambda_{10}$ & & & QL & $\begin{array}{c}\frac{1}{2}\left(C_{11} \cos ^{2} \varphi+C_{33} \sin ^{2} \varphi+\right. \\
\left.+C_{44}-2 C_{14} \cos \varphi \sin \varphi\right)+ \\
+\frac{1}{2} \sqrt{\left(C_{11} \cos ^{2} \varphi+C_{33} \sin ^{2} \varphi+C_{44}-\right.} \\
\frac{\left.-2 C_{14} \cos \varphi \sin \varphi\right)^{2}-4\left[\left(C_{11} \cos ^{2} \varphi+\right.\right.}{\left.+C_{44} \sin ^{2} \varphi-2 C_{14} \cos \varphi \sin \varphi\right) *} \\
\frac{*\left(C_{33} \sin ^{2} \varphi+C_{44} \cos ^{2} \varphi\right)-}{\left.-\left(\left(C_{13}+C_{14}\right) \cos \varphi \sin \varphi-C_{14} \cos ^{2} \varphi\right)^{2}\right]}\end{array}$ \\
\hline 3 & $\lambda_{11}$ & & & QS & $\begin{array}{c}\frac{1}{2}\left(C_{11} \cos ^{2} \varphi+C_{33} \sin ^{2} \varphi+\right. \\
\left.+C_{44}-2 C_{14} \cos \varphi \sin \varphi\right)- \\
\frac{-1}{2} \sqrt{\left(C_{11} \cos ^{2} \varphi+C_{33} \sin ^{2} \varphi+C_{44}-\right.} \\
\frac{\left.-2 C_{14} \cos \varphi \sin \varphi\right)^{2}-4\left[\left(C_{11} \cos ^{2} \varphi+\right.\right.}{\left.+C_{44} \sin ^{2} \varphi-2 C_{14} \cos \varphi \sin \varphi\right) *} \\
\frac{*\left(C_{33} \sin ^{2} \varphi+C_{44} \cos ^{2} \varphi\right)-}{\left.-\left(\left(C_{13}+C_{14}\right) \cos \varphi \sin \varphi-C_{14} \cos ^{2} \varphi\right)^{2}\right]}\end{array}$ \\
\hline 4 & $\lambda_{12}$ & {$[0-\sin \varphi \cos \varphi]$} & [100] & $\mathrm{S}$ & $\begin{array}{c}C_{66} \sin ^{2} \varphi+C_{44} \cos ^{2} \varphi- \\
-2 C_{14} \cos \varphi \sin \varphi+ \\
+\frac{\left(e_{11} \cos ^{2} \varphi+e_{14} \cos \varphi \sin \varphi\right)^{2}}{\varepsilon_{11}^{\eta} \cos ^{2} \varphi+\varepsilon_{33}^{\eta} \sin ^{2} \varphi}\end{array}$ \\
\hline 5 & $\lambda_{13}$ & & & QL & $\begin{array}{c}\frac{1}{2}\left(C_{11} \sin ^{2} \varphi+C_{33} \cos ^{2} \varphi+\right. \\
\left.+C_{44}+2 C_{14} \cos \varphi \sin \varphi\right)+ \\
+\frac{1}{2} \sqrt{\left(C_{11} \sin ^{2} \varphi+C_{33} \cos ^{2} \varphi+C_{44}+\right.} \\
\frac{\left.+2 C_{14} \cos \varphi \sin \varphi\right)^{2}-4\left[\left(C_{11} \sin ^{2} \varphi+\right.\right.}{+\frac{\left.C_{44} \cos ^{2} \varphi+2 C_{14} \cos \varphi \sin \varphi\right) *}{*\left(C_{33} \cos ^{2} \varphi+C_{44} \sin ^{2} \varphi\right)-}} \\
\frac{\left.-\left(-\left(C_{13}+C_{14}\right) \cos \varphi \sin \varphi-C_{14} \sin ^{2} \varphi\right)^{2}\right]}{}\end{array}$ \\
\hline 6 & $\lambda_{14}$ & & & QS & $\begin{array}{c}\frac{1}{2}\left(C_{11} \sin ^{2} \varphi+C_{33} \cos ^{2} \varphi+\right. \\
\left.+C_{44}+2 C_{14} \cos \varphi \sin \varphi\right)- \\
\frac{-\frac{1}{2} \sqrt{\left(C_{11} \sin ^{2} \varphi+C_{33} \cos ^{2} \varphi+C_{44}+\right.}}{+\frac{\left.2 C_{14} \cos \varphi \sin \varphi\right)^{2}-4\left[\left(C_{11} \sin ^{2} \varphi+\right.\right.}{\left.+C_{44} \cos ^{2} \varphi+2 C_{14} \cos \varphi \sin \varphi\right) *}} \\
\frac{*\left(C_{33} \cos ^{2} \varphi+C_{44} \sin ^{2} \varphi\right)-}{\left.-\left(-\left(C_{13}+C_{14}\right) \cos \varphi \sin \varphi-C_{14} \sin ^{2} \varphi\right)^{2}\right]}\end{array}$ \\
\hline
\end{tabular}


of echo pulses is shown in Fig. 3. The resonant frequency of the piezoelectric transducer in the experiments was $28 \mathrm{MHz}$.

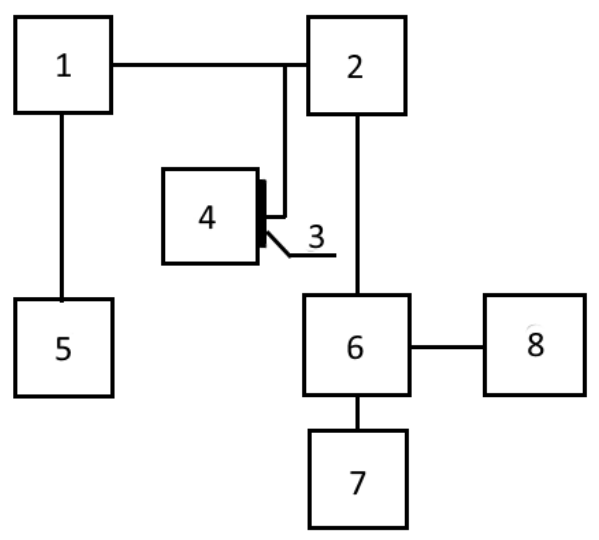

Fig. 2. Block diagram of the automated pulse-echo method. 1 - G5-66 pulse generator, 2 - signal limiting amplifier, 3 - piezoelectric transducer, 4 - sample, 5-AFG 3252 master generator, 6 - DPO 72004 oscilloscope, 7 - FS725 rubidium frequency standard, 8 - personal computer

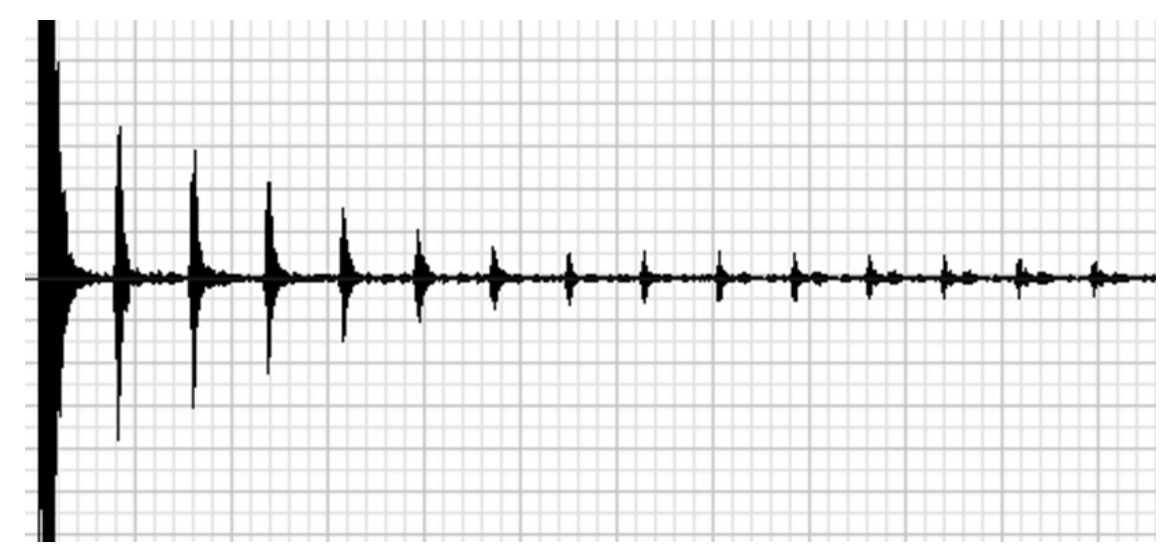

Fig. 3. A series of reflected echo pulses for a longitudinal wave in the direction [100] of the single crystal $\mathrm{YAl}_{3}\left(\mathrm{BO}_{3}\right)_{4}$

The quasi-static measurements of piezoelectric moduli $\mathrm{d}_{11}$ and $\mathrm{d}_{14}$ were carried out at the equipment, the block diagram of which is given in Fig. 4.

When measuring, the test sample 6 is placed in the holder 7 of the DMA 242 C 1 device, and adjustable static $\mathrm{F}_{\text {stat }}$ and dynamic $\mathrm{F}_{\text {dyn }}$ loads with a total amplitude in the range of $0 \div 8 \mathrm{H}$ with a frequency of up to $100 \mathrm{~Hz}$ are applied to it. Electric charges on the surface of the piezoelectric sample under load are converted by the charge amplifier 4 into the voltage recorded by the oscilloscope 3. An example of voltage measurement is shown in Fig. 5.

The value of the piezoelectric modulus is calculated in accordance with the formula:

$$
d_{i \lambda}=\frac{q}{F}=\frac{U S_{l}}{K_{\alpha} F S_{e}},
$$

where $d_{i \lambda}$ is the measured piezoelectric modulus, $\mathrm{q}$ is electrodes charge, $\mathrm{F}_{d y n}$ is the dynamic force amplitude, $\mathrm{U}$ is the voltage amplitude at the charge amplifier output, $\mathrm{S}_{l}$ is the area of load application, $\mathrm{S}_{e}$ is the electrodes area, $\mathrm{K}_{\alpha}$ is the charge amplifier conversion coefficient. 


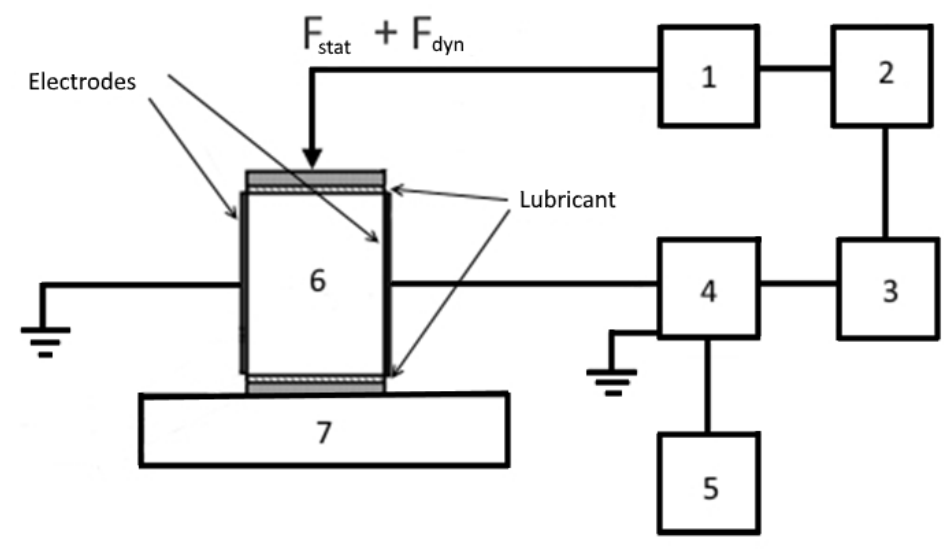

Fig. 4. Block diagram of the experimental method for measuring piezoelectric modules. A variant of measuring of the transverse as related to the direction of the electric polarization pressure is presented. 1 - DMA 242 C, 2 - personal computer, 3 - DPO 7104 oscilloscope, 4 - charge amplifier LE-41, 5 - power supply, 6 - sample, 7 - sample holder

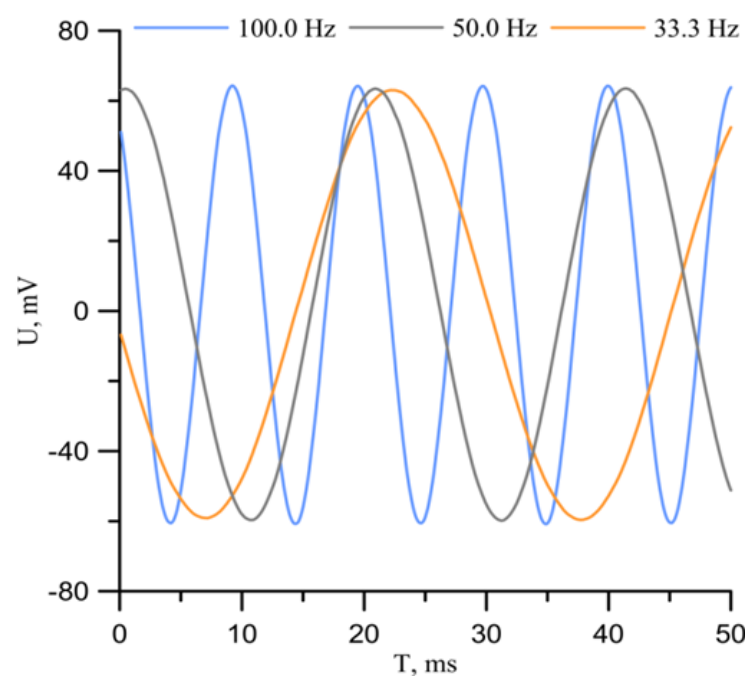

Fig. 5. Recording the voltage $\mathrm{U}$ on the sample when measuring piezoelectric moduli at different frequencies

The samples used in the experiments had the orientations given in Fig. 1. The linear dimensions of the samples were about 5-6 $\mathrm{mm}$, the accuracy of the faces orientation was not worse than \pm 3 ', the opposite faces flatness was 3 microns. To determine the low-frequency dielectric constant by the flat capacitor method, the plates with $\mathrm{x}$ and $\mathrm{R}$ cuts with a thickness of less than $0.5 \mathrm{~mm}$ and an area of about $1 \mathrm{~cm}^{2}$ were used.

The positive direction of $\mathrm{X}_{1}$ axis of the crystal-physical coordinate system was chosen from the correspondence of the measured BAW velocities to the solutions of equation (2) (Tab. 2) obtained for the $\mathrm{R}$ and $\mathrm{R}+90$ cuts (Fig. 1), in such a way that $\mathrm{C}_{14}<0$ was performed in both directions. The sign of piezoelectric constants was controlled by direct measurement of the piezoelectric effect. Mechanical compressive strain was considered negative. 


\section{Values of electromechanical constants}

Experimental values of BAW velocities for the studied directions are given in Tab. 3. Point out high values of the shear and longitudinal BAW velocities at a not very high density of the single crystal $3.72 \mathrm{~g} / \mathrm{cm}^{3}$ [25] under study.

Table 3. BAW velocities in $\mathrm{YAl}_{3}\left(\mathrm{BO}_{3}\right)_{4}$ single crystal at room temperature

\begin{tabular}{|c|c|c|c|}
\hline$\vec{n}$ & Mode & $\vec{U}$ & $(v \pm \Delta v), \mathrm{m} / \mathrm{s}$ \\
\hline \multirow{2}{*}{ [001] } & $\mathrm{L}$ & {$[001]$} & $8534 \pm 5$ \\
\hline & $\mathrm{S}$ & & $4488 \pm 1$ \\
\hline \multirow{3}{*}{ [100] } & $\mathrm{L}$ & {$[100]$} & $10587 \pm 2$ \\
\hline & $\mathrm{S}$ & & $4020 \pm 1$ \\
\hline & $\mathrm{S}$ & & $5474 \pm 1$ \\
\hline \multirow{3}{*}{010[} & $\mathrm{S}$ & {$[100]$} & $5412 \pm 3$ \\
\hline & QL & & $10453 \pm 1$ \\
\hline & QS & & $4435 \pm 1$ \\
\hline \multirow{3}{*}{ 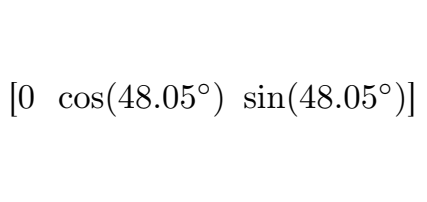 } & $\mathrm{S}$ & {$[100]$} & $4205 \pm 1$ \\
\hline & $\mathrm{QL}$ & & $9202 \pm 3$ \\
\hline & QS & & $5521 \pm 1$ \\
\hline \multirow{3}{*}[0-\operatorname{sin}(48.05^{\circ})\operatorname{cos}(48.05^{\circ})]{} & S & [100] & $5486 \pm 1$ \\
\hline & $\mathrm{QL}$ & & $8680 \pm 3$ \\
\hline & QS & & $5610 \pm 1$ \\
\hline
\end{tabular}

The values of $\mathrm{C}_{i j k l}$ calculated in accordance with the ratios of Tab. 1 and 2 are given in Tab. 4 compared to the data for other crystals.

In quasi-static measurements, the longitudinal piezoelectric modulus $\mathrm{d}_{11}$ was determined according to the formula (4) when mechanical compressive stress was applied along axis $\mathrm{X}_{1}$ (Fig. $1 \mathrm{~b}$ ) and charge detection was recorded in the same direction. The sign of the piezoelectric modulus was found by determining the direction of the electric induction vector with respect to the positive direction of $\mathrm{X}_{1}$ axis from equation (3). To determine $\mathrm{d}_{14}$, in contrast to $\mathrm{d}_{11}$, a mechanical compressive stress was applied to $R$ and $R+90$ faces (Fig. $1 \mathrm{~b}$ ). In this case, there were piezoelectric modules $\mathrm{d}_{12}^{\prime}$ and $\mathrm{d}_{12}^{\prime \prime}$ respectively. In this case the value of the piezoelectric modulus $\mathrm{d}_{14}$ can be found from the equations

$$
d_{14}=\frac{d_{12}^{\prime}+d_{11} \cos ^{2} \varphi}{\sin \varphi \cos \varphi}
$$


Table 4. Values of elastic constants $\mathrm{YAl}_{3}\left(\mathrm{BO}_{3}\right)_{4}$ at room temperature compared to the data for other oxyborate single crystals, $C_{66}=\left(C_{11}-C_{12}\right) / 2$

\begin{tabular}{|c|c|c|c|c|c|c|}
\hline \multirow{4}{*}{$\begin{array}{c}\text { Elastic } \\
\text { constants }\end{array}$} & \multicolumn{6}{|c|}{ Values of elastic constants, $10^{10} \mathrm{~N} / \mathrm{m}^{2}$} \\
\hline & \multirow{3}{*}{$\begin{array}{c}\text { This work } \\
\mathrm{YAl}_{3}\left(\mathrm{BO}_{3}\right)_{4}\end{array}$} & \multirow{2}{*}{\multicolumn{2}{|c|}{$\frac{[13]}{\mathrm{RFe}_{3}\left(\mathrm{BO}_{3}\right)_{4}}$}} & \multirow{2}{*}{\multicolumn{2}{|c|}{$\frac{[14]}{\mathrm{HoMe}_{3}\left(\mathrm{BO}_{3}\right)_{4}}$}} & \multirow{3}{*}{$\begin{array}{c}{[15]^{*}} \\
\mathrm{TbFe}_{3}\left(\mathrm{BO}_{3}\right)_{4}\end{array}$} \\
\hline & & & & & & \\
\hline & & $\mathrm{R}=\mathrm{Nd}$ & $\mathrm{R}=\mathrm{Sm}$ & $\mathrm{Me}=\mathrm{Fe}$ & $\mathrm{Me}=\mathrm{Al}$ & \\
\hline $\mathrm{C}_{11}$ & $40.47 \pm 0.05$ & 31.9 & 32.4 & 37 & 39.5 & 27.2 \\
\hline $\mathrm{C}_{12}$ & $21.14 \pm 0.05$ & 17.4 & 19.4 & 12.5 & 13.1 & 12.2 \\
\hline $\mathrm{C}_{13}$ & $9.75 \pm 0.05$ & 11.7 & - & 7.2 & 6.1 & - \\
\hline $\mathrm{C}_{14}$ & $-2.35 \pm 0.1$ & 2.96 & 2.86 & 3 & 1 & 4.76 \\
\hline $\mathrm{C}_{33}$ & $27.09 \pm 0.05$ & 21.4 & 21.4 & 15.9 & 17.3 & 21.1 \\
\hline $\mathrm{C}_{44}$ & $7.49 \pm 0.01$ & 4.9 & 5.05 & 6.8 & 6.4 & 7.54 \\
\hline
\end{tabular}

*Measurements are performed at liquid nitrogen temperature

or

$$
d_{14}=\frac{d_{12}^{\prime \prime}+d_{11} \sin ^{2} \varphi}{-\sin \varphi \cos \varphi},
$$

The results of quasi-static measurements are presented in Tab. 5.

Table 5. The values of the piezoelectric moduli $\mathrm{d}_{i \lambda}$ in single crystal $\mathrm{YAl}_{3}\left(\mathrm{BO}_{3}\right)_{4}$ at room temperature

\begin{tabular}{|c|c|c|c|c|}
\hline Piezoelectric moduli & $\mathrm{d}_{11}$ & $\mathrm{~d}_{12}^{\prime}$ & $\mathrm{d}_{12}^{\prime}$ & $\mathrm{d}_{14}$ \\
\hline Values of moduli, $10^{-12} \mathrm{C} / \mathrm{N}$ & $-6.0 \pm 0.3$ & $-0.9 \pm 0.1$ & $7.0 \pm 0.2$ & $-7.2 \pm 0.4$ \\
\hline
\end{tabular}

After determining the values of the piezoelectric moduli and elastic moduli, it becomes possible to determine the values of the piezoelectric constants $e_{11}$ and $e_{14}$. This can be done from the equations 3 and 6 of Tab. 1 and the equations 1 and 4 of Tab. 2, as well as using the formula (1), which gives the following equalities

$$
\begin{aligned}
& e_{11}=2 C_{66} d_{11}+C_{14} d_{14}, \\
& e_{14}=2 C_{14} d_{11}+C_{44} d_{14} .
\end{aligned}
$$

Equations (7) and (8) determine the sign of the constants $e_{11}$ and $e_{14}$. Note that the obtained values of the piezoelectric constants $\mathrm{e}_{11}$ and $\mathrm{e}_{14}$ from the acoustic measurements, as well as the values calculated from equations (7) and (8) coincided within the experimental error. The values $\mathrm{e}_{11}$ and $\mathrm{e}_{14}$ of the single crystal $\mathrm{YAl}_{3}\left(\mathrm{BO}_{3}\right)_{4}$ are presented in Tab. 6 compared to the known 
data for oxyborates of other authors. The high-frequency values of the dielectric constant $\varepsilon_{i j}^{\eta}$ were calculated on the basis of the experimental values $\varepsilon_{i j}^{\sigma}$ using the formula [22]

$$
\varepsilon_{m n}^{\sigma}-\varepsilon_{m n}^{\eta}=d_{m i j} d_{n k l} C_{i j k l}^{E} .
$$

Table 6 . Values of piezoelectric $\mathrm{e}_{i j k}$ and dielectric $\varepsilon_{i j}^{\eta}$ constants at room temperature

\begin{tabular}{|c|c|c|c|c|c|}
\hline \multirow{3}{*}{ Constants } & \multicolumn{5}{|c|}{ Values of constants } \\
\hline & \multirow{2}{*}{$\begin{array}{l}\text { This work } \\
\mathrm{YAl}_{3}\left(\mathrm{BO}_{3}\right)_{4}\end{array}$} & \multicolumn{2}{|c|}{$[13]$} & \multicolumn{2}{|c|}{$[14]$} \\
\hline & & $\mathrm{NdFe}_{3}\left(\mathrm{BO}_{3}\right)_{4}$ & $\mathrm{SmFe}_{3}\left(\mathrm{BO}_{3}\right)_{4}$ & $\mathrm{HoFe}_{3}\left(\mathrm{BO}_{3}\right)_{4}$ & $\mathrm{HoAl}_{3}\left(\mathrm{BO}_{3}\right)_{4}$ \\
\hline \multicolumn{6}{|c|}{ Piezoelectric constants $\mathrm{e}_{i j k}, \mathrm{C} / \mathrm{m}^{2}$} \\
\hline $\mathrm{e}_{11}$ & $-1.06 \pm 0.07$ & 1.4 & 1.4 & 0.99 & 1.75 \\
\hline $\mathrm{e}_{14}$ & $-0.27 \pm 0.04$ & 0.4 & & 1.11 & 0.5 \\
\hline \multicolumn{6}{|c|}{ Dielectric constants, $\varepsilon_{i j}^{\eta} / \varepsilon_{0}$} \\
\hline$\varepsilon_{11}^{\eta} / \varepsilon_{0}$ & $11.7 \pm 0.1$ & & & & \\
\hline$\varepsilon_{33}^{\eta} / \varepsilon_{0}$ & $11.1 \pm 0.1$ & & & & \\
\hline
\end{tabular}

\section{Anisotropy of BAW characteristics}

Based on the obtained values of the material constants of $\mathrm{YAl}_{3}\left(\mathrm{BO}_{3}\right)_{4}$ crystal elastic moduli, piezoelectric coefficient and dielectric constant, anisotropy for bulk acoustic waves characteristics in the base planes was calculated. The values of BAW phase velocities were calculated on the basis of the Green-Christoffel equations (2). The calculation of electromechanical coupling coefficients (EMCC) $\mathrm{k}^{2}$ and the angles of deviation of the elastic wave energy flow $\gamma$ from the wave normal were calculated using the formulas [26]. To simulate the anisotropy of BAW characteristics, the software package [27], where all calculations are performed in a triaxial orthogonal crystal physical coordinate system (CPCS) was used.

The anisotropy of BAW parameters in the (001) plane is demonstrated in Fig. 6. In this plane, the change in BAW velocities of longitudinal (QL) and fast shear (QFS) waves is relatively small. In particular, the value of the phase velocity QFS in the direction [100] is $5479.8 \mathrm{~m} / \mathrm{s}$, but at an angle of $30^{\circ}$ it is $5407.3 \mathrm{~m} / \mathrm{s}$ (Fig. $6 \mathrm{a}$ ). In the plane (001) all BAW are piezo-active. The maximum EMCC k $\mathrm{k}^{2}$ value is close to 0.1 and is reached in the direction at an angle of $30^{\circ}$ with the direction [100] for the elastic wave QFS, but, at the same time, the maximum value of the energy flow deviation from the wave normal $\gamma=10.7^{\circ}$ for QFS is reached as well. The maximum value $\gamma=18.5^{\circ}$ is reached for a slow shear wave QSS at an angle of $15^{\circ}$ with the direction [100]. It should be noted that in the direction [100] for the QL wave, the maximum value of $\mathrm{k}^{2}$, close to 0.03 , is reached, but the value is $\gamma=0^{\circ}$, which may be of practical importance. In Fig. 6 and in the other figures, the dots indicate the experimental values of BAW velocities.

The similar BAW characteristics of crystal $\mathrm{YAl}_{3}\left(\mathrm{BO}_{3}\right)_{4}$ in plane (010) are presented in Fig. 7. In $\mathrm{Y}$-cut, all BAW are also piezo-active, but the maximum value of $\mathrm{k}^{2}$ is reached for the $\mathrm{QL}$ 


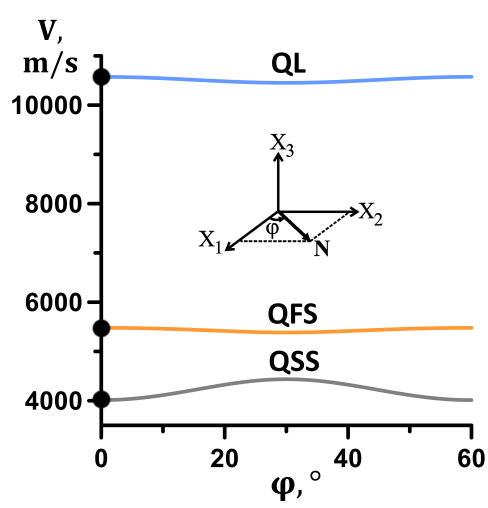

(a)

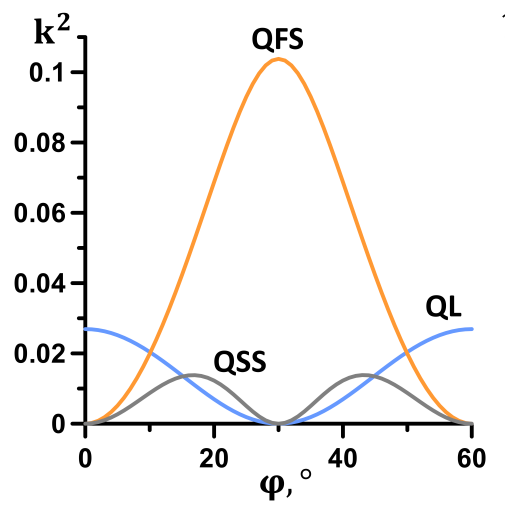

(b)

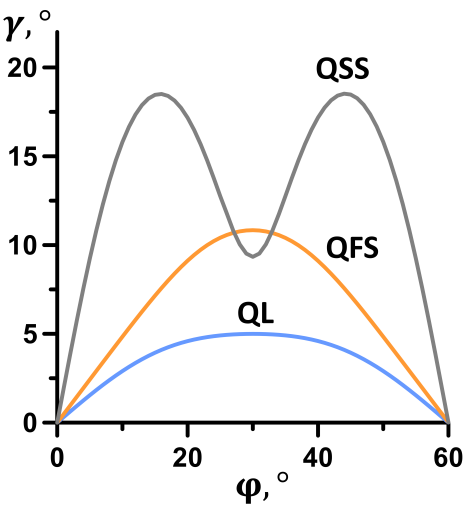

(c)

Fig. 6. Anisotrop y of BAW characteristics in plane (001)

wave in the direction [100]. For QFS and QSS waves it is much smaller (Fig. 7 b). However, the energy flow deviation in plane (010) is considerably larger compared to (001). The maximum value for QSS wave is $\gamma=32.5^{\circ}$ at an angle of $35^{\circ}$ with the axis [001] (Fig. 7c).

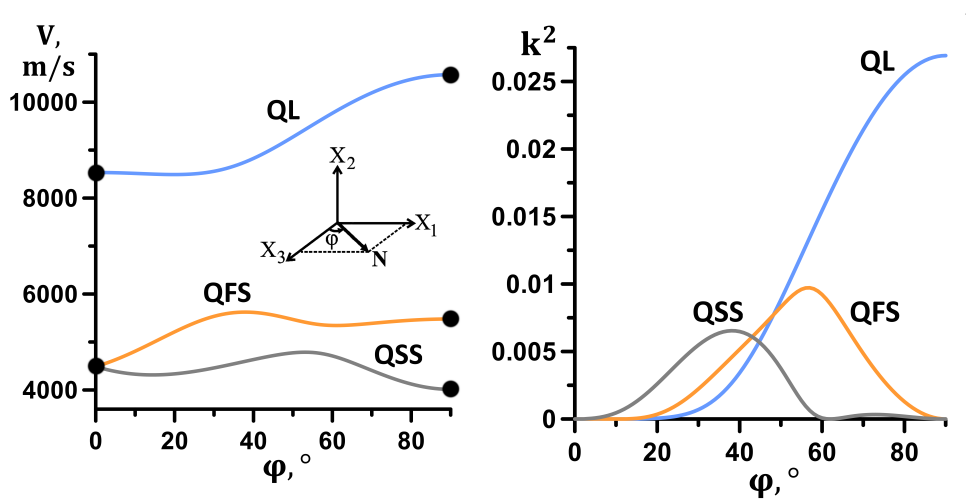

(a) (b)

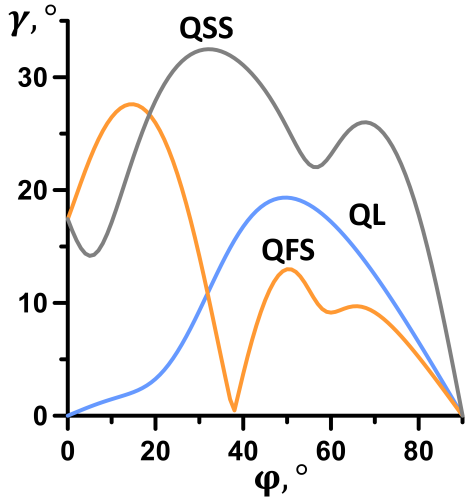

(c)

Fig. 7. Anisotropy of BAW characteristics in plane (010)

There is a distinctive feature in plane (100) - the presence of 4 acoustic axes (Fig. 8), and only in the direction [001] (the axis of symmetry of order 3) the presence of the acoustic axis is determined by the crystal symmetry. Only one of the shear waves is piezo-active. The solutions "exchange" takes place in the acoustic axes' region at an angle of $25.5^{\circ}$ and $143^{\circ}$ with the direction [100]. The maximum value of EMCC k $\mathrm{k}^{2}=0.12$ is reached at an angle of $15^{\circ}$ with the direction [100] for QFS. It is necessary to note large values of the energy flow deviation angles from the wave normal to $\gamma=29^{\circ}$ for a slow shear wave (Fig. $8 \mathrm{c}$ ).

The similar BAW characteristics of crystal $\mathrm{YAl}_{3}\left(\mathrm{BO}_{3}\right)_{4}$ in the plane (110) of CFCS are presented in Fig. 9. In the plane (110) all BAW are also piezo-active, as well as maximum values of $\mathrm{k}^{2}$, close to 0.05 for fast and slow BAW respectively, (Fig. $9 \mathrm{~b}$ ). However, in these directions, the angles of energy flow deviation from the wave normal are significant (Fig. $9 \mathrm{c})$. 


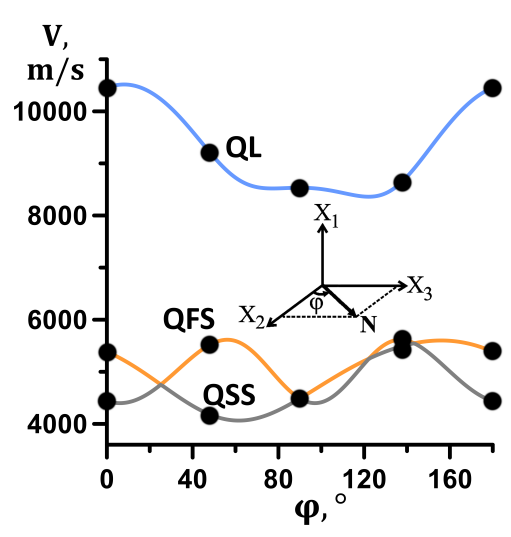

(a)

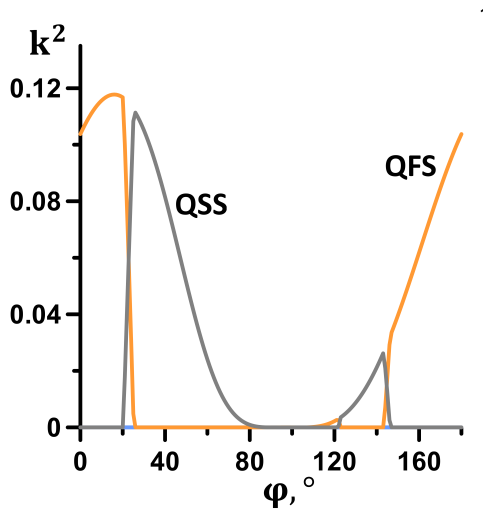

(b)

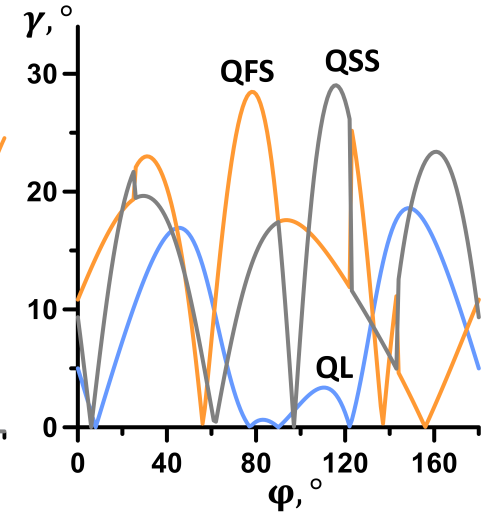

(c)

Fig. 8. Anisotropy of BAW characteristics in plane (100)

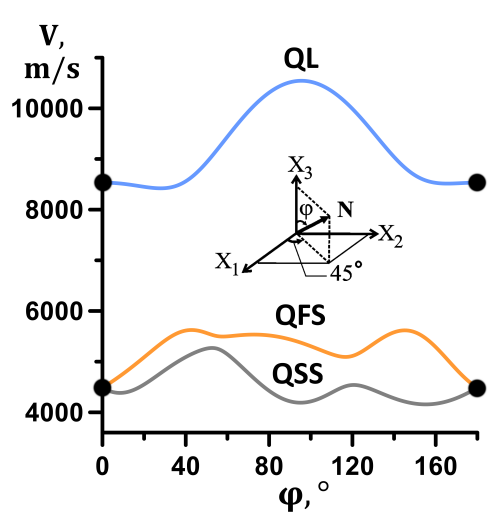

(a)

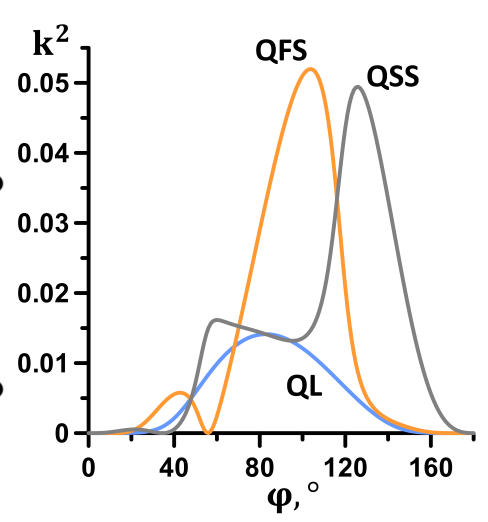

(b)

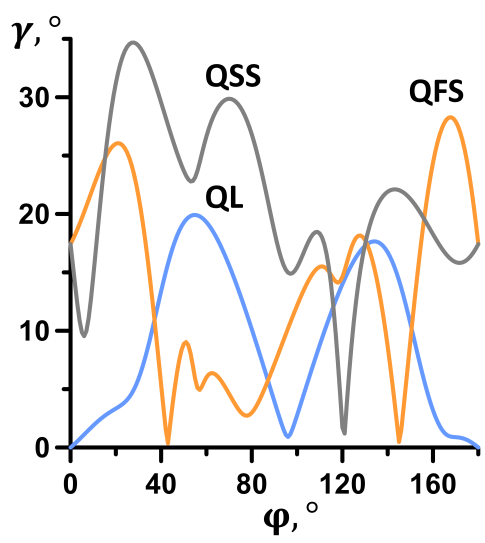

(c)

Fig. 9. Anisotropy of BAW characteristics in plane $(\overline{1} 10)$

\section{Anisotropy of SAW characteristics}

To calculate SAW characteristics, it is necessary to supplement the equations of motion (2) with boundary conditions, which are equality of the normal components of the stress tensor to zero and continuity of the electric induction vector at the crystal-vacuum interface: $\left.\tau_{3 j}\right|_{x_{3}=0}=0$; $D_{3}=\left.D^{v a c}\right|_{x_{3}=0}[28]$. The anisotropy of SAW characteristics is analyzed using the software package [29] in the working orthogonal coordinate system, where axis $\mathrm{X}_{3}$ is directed along the outer normal to the layer surface, and axis $\mathrm{X}_{1}$ coincides with the direction of wave propagation. SAW characteristics of crystal $\mathrm{YAl}_{3}\left(\mathrm{BO}_{3}\right)_{4}$ in plane $(001)$ are presented in Fig. 10. The values of the SAW phase velocity are in the range from $3958.9 \mathrm{~m} / \mathrm{s}$ to $4276.1 \mathrm{~m} / \mathrm{s}$. The maximum value of EMCC $\mathrm{k}^{2}=0.0013$ in the direction of elastic wave propagation at an angle of $16^{\circ}$ with the axis [100], but the maximum angle of energy flow deviation from the sagittal plane $\gamma=12.9^{\circ}$ is also reached here.

In plane (010), the maximum value of EMCC k${ }^{2}=0.011$ is reached in the direction of the elastic wave propagation at an angle of $28^{\circ}$ with the axis [001] (Fig. 11), but the angle of the 


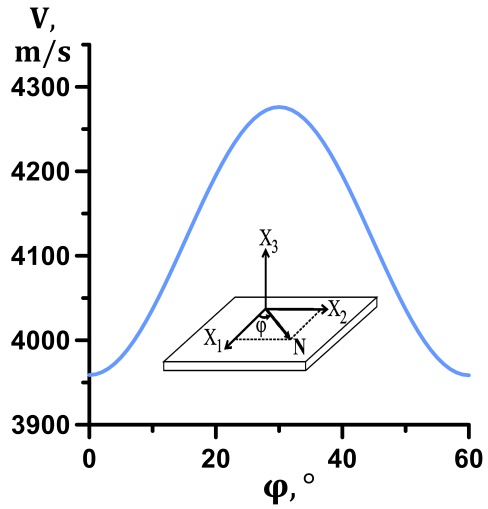

(a)

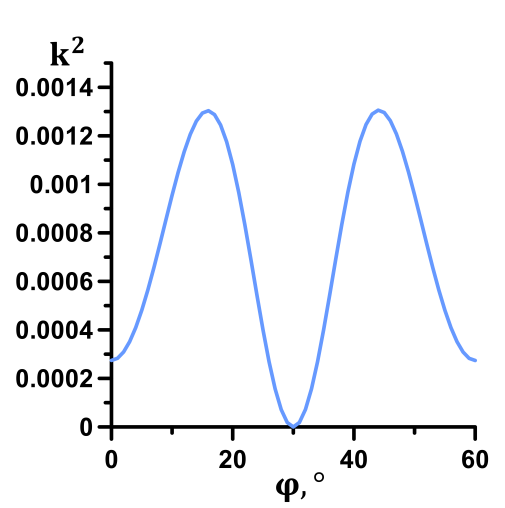

(b)

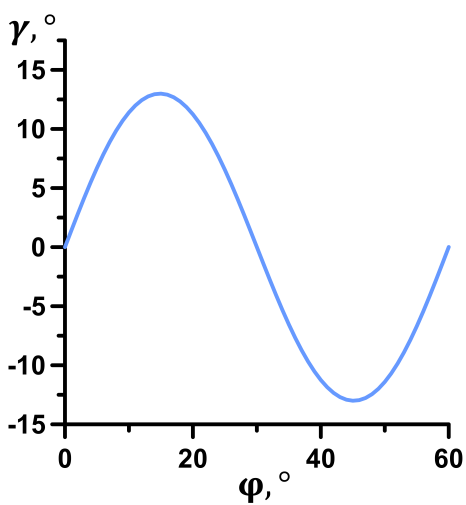

(c)

Fig. 10. Anisotropy of SAW characteristics in plane (001)

energy flow deviation from the sagittal plane is $\gamma=5.1^{\circ}$. The maximum value of the angle of the energy flow deviation from the sagittal plane is $\gamma=18.1^{\circ}$ is achieved at an angle of $17^{\circ}$ with the axis [001].

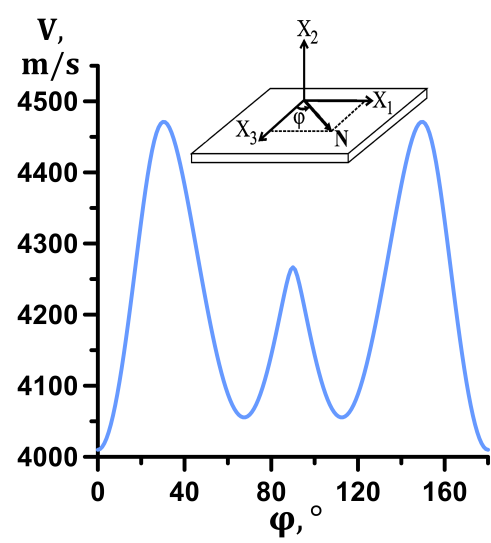

(a)

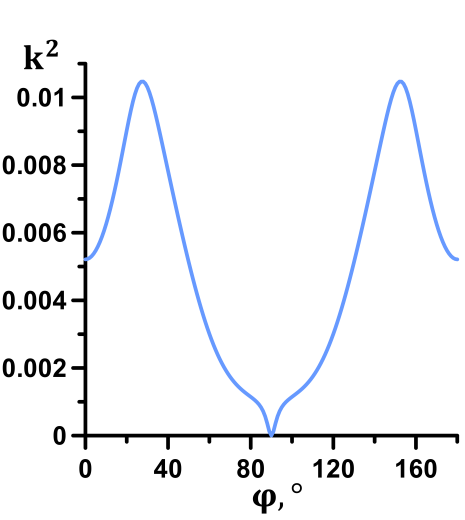

(b)

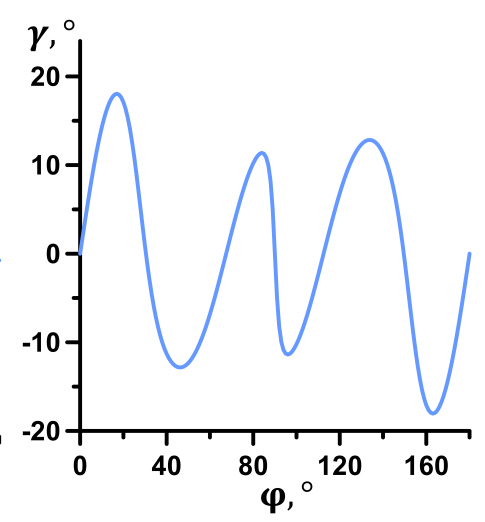

(c)

Fig. 11. Anisotropy of SAW characteristics in plane (010)

The similar SAW characteristics of crystal $\mathrm{YAl}_{3}\left(\mathrm{BO}_{3}\right)_{4}$ in plane (100) are presented in Fig. 12. The maximum value of $\mathrm{EMCC}^{2} \approx 0.012$ is reached in the direction of the elastic wave propagation at an angle of $29^{\circ}$ with the axis [010] (Fig. 12), but the energy flow deviation angle from the sagittal plane is $\gamma=10.3^{\circ}$. At an angle of $159^{\circ}$ with the axis [010] and the value of $\mathrm{k}^{2}=0.011$ the angle $\gamma=8.9^{\circ}$.

SAW characteristics of crystal $\mathrm{YAl}_{3}\left(\mathrm{BO}_{3}\right)_{4}$ in the $\mathrm{X}$ boule axis, Euler angles $\left(0^{\circ}, \varphi, 0^{\circ}\right)$ are given in Fig. 13. The energy flow deviation angle from the sagittal plane in the entire interval is zero, EMCC reaches values close to 0.008 .

SAW characteristics of crystal $\mathrm{YAl}_{3}\left(\mathrm{BO}_{3}\right)_{4}$ for $\mathrm{Y}$ cylinder axis, Euler angles $\left(0^{\circ}, \varphi, 90^{\circ}\right)$ are presented in Fig. 14. In this case, the symmetry axis 2 is orthogonal to the sagittal plane, therefore, there are two surface waves in this section - the Rayleigh wave polarized in the sagittal plane and the Bleustein-Gulyaev piezo-active wave. The peculiarity of this section is the fact that the phase velocity value of the Rayleigh wave is greater than the slow shear wave in the interval when the fast shear wave becomes piezo-active (Fig. 14). The energy flow deviation 


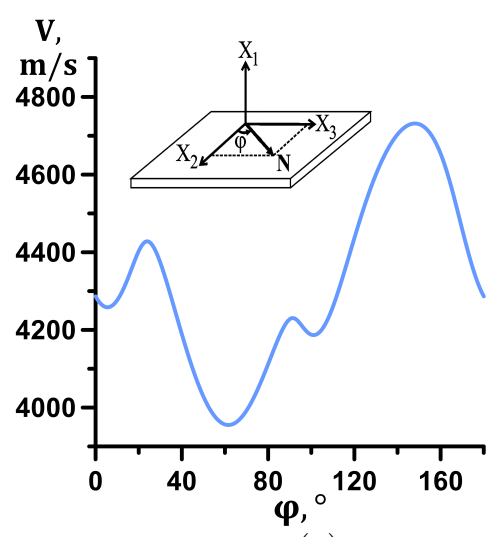

(a)

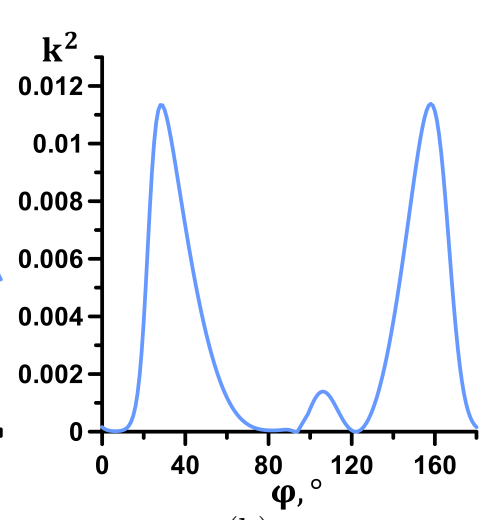

(b)

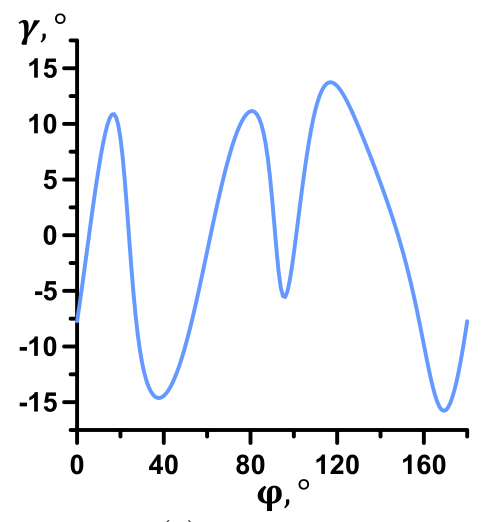

(c)

Fig. 12. Anisotropy of SAW characteristics in plane (100)

angle from the sagittal plane is also zero in the entire interval, but EMCC can exceed the values of $\mathrm{k}^{2}=0.013$.

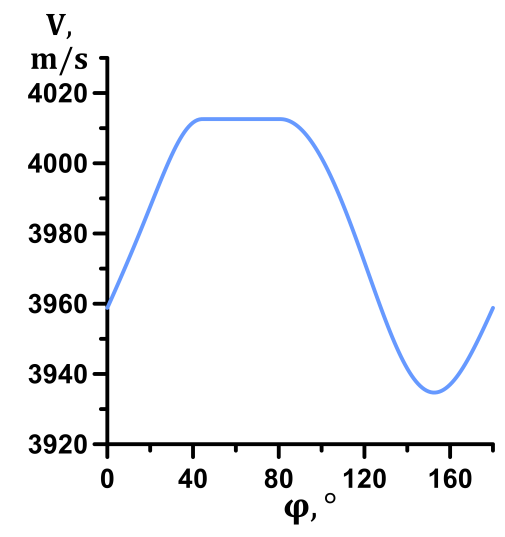

(a)

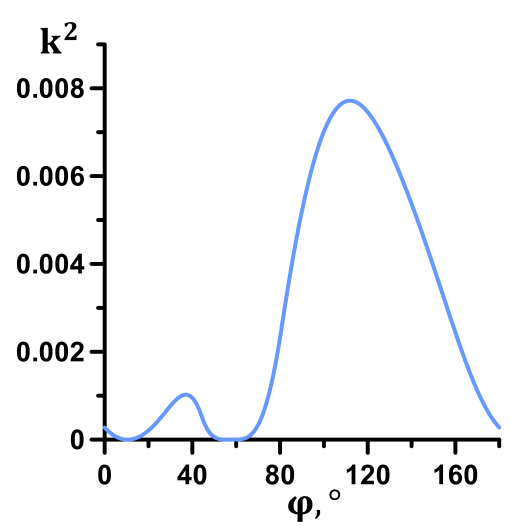

(b)

Fig. 13. Anisotropy of SAW characteristics for the X boule axis, Euler angles $\left(0^{\circ}, \varphi, 0^{\circ}\right)$

\section{Conclusion}

The carried out precision acoustic and quasi-static measurements made it possible to determine the values of linear electromechanical material constant of single crystals $\mathrm{YAl}_{3}\left(\mathrm{BO}_{3}\right)_{4}$ with good precision. Despite the small value of the single crystal density of $3.72 \mathrm{~g} / \mathrm{cm}^{3}$, the shear BAW velocities exceed $4000 \mathrm{~m} / \mathrm{s}$, the longitudinal BAW $8000 \mathrm{~m} / \mathrm{s}$, and in a number of directions $10000 \mathrm{~m} / \mathrm{s}$. The value of the longitudinal modulus of elasticity $\mathrm{C}_{11}=40.5 \cdot 10^{10} \mathrm{~N} / \mathrm{m}^{2}$.

Both acoustic ultrasonic pulse-echo method and quasi-static measurements of piezoelectric constants within the margin of error give the same, relatively small values $\mathrm{e}_{11}=-1.06 \mathrm{C} / \mathrm{m}^{2}$ and $\mathrm{e}_{14}=-0.27 \mathrm{C} / \mathrm{m}^{2}$. At the same time, the study of the anisotropy of BAW characteristics demonstrates the existence of directions in the (100) and (001) planes in the single crystal under study, in which the electromechanical coupling coefficient $\mathrm{k}$ for a fast shear BAW exceeds $30 \%$, as in strong piezoelectrics. 


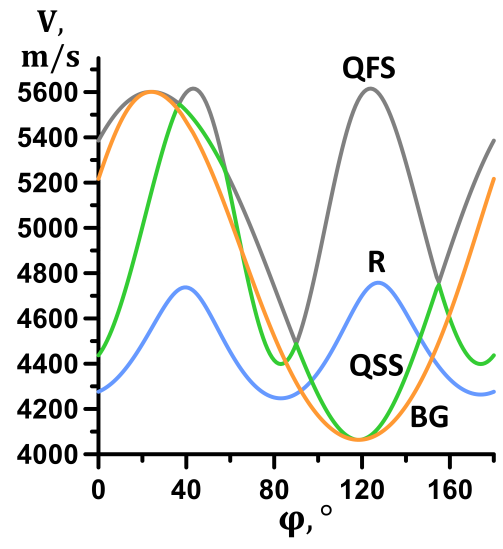

(a)

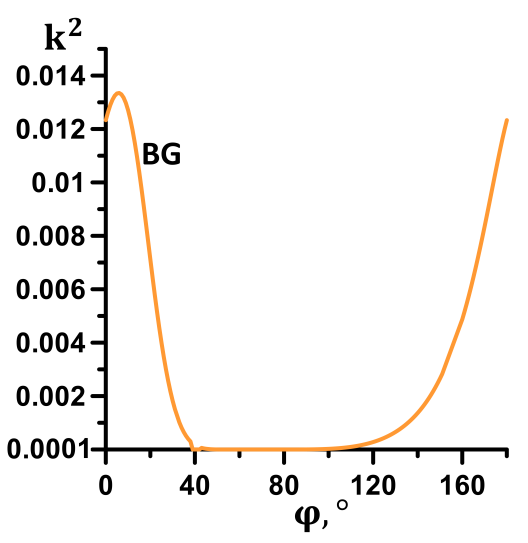

(b)

Fig. 14. Anisotropy of SAW characteristics for Y cylinder axis $(0, \varphi, 90)$

The study of the anisotropy of the BAW and SAW characteristics demonstrates a number of other features of the yttrium aluminum borates electromechanical properties manifestation. For instance, in plane (100) 4 acoustic axes are observed, and only one of them is symmetrically conditioned. For X boule axis, a range of angles where the velocity of the Rayleigh SAW exceeds the velocity of the slow shear BAW is observed.

The reported study was funded by Russian Foundation for Basic Research project no. 18-42240016, Government of Krasnoyarsk Territory, Krasnoyarsk Regional Fund of Science, to the research project: "Electromechanical Properties and Anisotropy of Acoustic Wave Propagation in Ytrium Aluminoborates Single Crystals".

\section{References}

[1] D.Khomskii, Trend: Classifying multiferroics: Mechanisms and effects, Physics, 2(2009), 20.

[2] R.Ramesh, N.A.Spaldin, Multiferroics: progress and prospects in thin films, Nanoscience And Technology: A Collection of Reviews from Nature Journals, (2010), 20-28.

[3] N.A.Spaldin, M.Fiebig The renaissance of magnetoelectric multiferroics, Science, 309(2005), no. 5733, 391-392.

[4] N.V.Volkov, et al., Magnetization, magnetoelectric polarization and heat capacity $\mathrm{HoGa}_{3}\left(\mathrm{BO}_{3}\right)_{4}$, JETP Letters, 99(2014), no. 2, 72-80.

[5] A.I.Popov, D.I.Plokhov, A.K.Zvezdin, Quantum theory of magnetoelectricity in rare-earth multiferroics: Nd, Sm, and Eu ferroborates, Physical Review B, 87(2013), no. 2, 024413.

[6] A.K.Zvezdin, About the magnetoelectric effects in the gadolinium iron borate $\mathrm{GdFe}_{3}(\mathrm{BO} 3)_{4}$, JETP Letters, 81(2005), no. 6, 335-340.

[7] K.C.Liang et al., Giant magnetoelectric effect in $\mathrm{HoAl}_{3}\left(\mathrm{BO}_{3}\right)_{4}$, Physical Review B, 83(2011), no. 18,180417 .

[8] A.A.Mukhin, et al., The giant magnetodielectric effect in the multiferroic $\mathrm{SmFe}_{3}(\mathrm{BO} 3)_{4}$, JETP Letters, 93(2011), no. 5, 305-311. 
[9] K.N.Gorbachenya et al., High-frequency $\mathrm{Er}^{3+}, \mathrm{Yb}^{3+}: \mathrm{YAl}_{3}\left(\mathrm{BO}_{3}\right)_{4}$ microchip laser with longitudinal diode pumping, Devices and Methods of Measurement, 5(2012), no. 2.

[10] A.S.Aleksandrovsky et al., Upconversion luminescence of $\mathrm{YA}_{3}\left(\mathrm{BO}_{3}\right)_{4}:\left(\mathrm{Yb}^{3+}, \mathrm{Tm}^{3+}\right)$ crystals, Journal of Alloys and Compounds, 496(2010), no. 1-2, L18-L21.

[11] G.Wang et al., $\mathrm{Cr}^{3}$-doped borates-potential tunable laser crystals? Radiation effects and defects in solids, 136(1995), no. 1-4, 43-46.

[12] L.Zheng et al., $>1 \mathrm{MW}$ peak power at $266 \mathrm{~nm}$ in nonlinear $\mathrm{YAl}_{3}\left(\mathrm{BO}_{3}\right)_{4}(\mathrm{YAB})$ single crystal, Lasers and Electro-Optics (CLEO), 2015 Conference on, IEEE, 2015, 1-2.

[13] T.N.Gaydamak et al., Elastic and piezoelectric moduli of Nd and Sm ferroborates, Low Temperature Physics, 41(2015), no. 8, 614-618.

[14] V.I.Zinenko et al., Oscillation spectra, elastic, piezoelectric and magnetoelectric properties of crystals $\mathrm{HoFe}_{3}\left(\mathrm{BO}_{3}\right)_{4}$ and $\mathrm{HoAl}_{3}\left(\mathrm{BO}_{3}\right)_{4}$, Journal of Experimental and Theoretical Physics, 144(2013), no. 6, 1174-1183.

[15] G.A.Zvyagina et al., Magnetoelastic effects in terbium ferroborate, Low-temperature physics, 34(2008), no. 1, 1142-1151 (in Russian).

[16] W.Mason, Physical Acoustics. Vol. 1. Ultrasound Research Methods and Devices, Moscow, Mir, 1966 (in Russian).

[17] P.P.Turchin et al., Pulsed automated measurements of elastic waves velocities in crystals, Polzunovsky Vestnik, 2011, no. 3-1, 143-147 (in Russian).

[18] K.S.Aleksandrov, B.P.Sorokin, P.P.Turchin, D.A.Glushkov, Non-linear piezoelectricity in $\mathrm{La}_{3} \mathrm{Ga}_{5} \mathrm{SiO}_{14}$ piezoelectric single crystal, Ferroelectrics Letters, 14(1992), no. 5-6, 115-126.

[19] B.P.Sorokin, P.P.Turchin, S.I.Burkov, D.A.Glushkov, K.S.Aleksandrov, Influence of static electric field, mechanical pressure and temperature on the propagation of acoustic waves in $\mathrm{La}_{3} \mathrm{Ga}_{5} \mathrm{SiO}_{14}$ piezoelectric single crystals, Proc. of 1996 IEEE Int. Frequency Control Symp, USA, Hawaii, Honolulu, 1996, 161-169.

[20] V.A.Golovin, I.A.Kaplunov, O.V.Malyshkina, B.B.Ped'ko, A.A.Movchikova, Physical principles, research methods and practical application of piezomaterials, Moscow, Tekhnosfera, 2013.

[21] M.V.Bogush, Design of piezoelectric sensors based on spatial electrothermoelastic models, Moscow, Tekhnosfera, 2014.

[22] J.Nye, Physical properties of crystals, Moscow, Foreign literature, 1967.

[23] Yu.I.Sirotin, M.P.Shaskol'skaya, Principles of Crystal Physics, 1979.

[24] E.Dieulesaint, D.Royer, Elastic waves in solids: applications to signal processing, John Wiley \& Sons, 1980.

[25] E.L.Belokoneva et al., Crystal structure of $\mathrm{YAl}_{3}(\mathrm{BO} 3)_{4}$, Journal of Structural Chemistry, 22(1981), no. 3. 476-478.

[26] K.S.Alexandrov, B.P.Sorokin, B S.I.urkov, Effective piezoelectric crystals for acoustoelectronics, piezotechnics and sensors, Vol. 1, Novosibirsk, Publishing House of the Siberian Branch of the Russian Academy of Sciences, 2007. 
[27] S.I.Burkov, S B.P.orokin, Calculation of the anisotropy of bulk acoustic waves propagation in piezocrystals under the effect of a uniform external electric field, Certificate no. 2009613152 dated 06.06.2009.

[28] G.W.Farnell, Acoustic Surface Waves Topics in Applied Physics, Vol. 24, ed. A. A. Oliner, 1978.

[29] S.I.Burkov, B.P.Sorokin, Calculation of the anisotropy of surface acoustic waves propagation in piezocrystals under the effect of a uniform external electric field, Certificate no. 2009613150 dated 18.06.2009.

\section{Электромеханические свойства и анизотропия характеристик акустических волн \\ в монокристаллах $\mathrm{YAl}_{3}\left(\mathrm{BO}_{3}\right)_{4}$}

Павел П. Турчин

Институт инженерной физики и радиоэлектроники

Сибирский федеральный университет

Свободный, 79, Красноярск, 660041

Институт физики им. Л. В. Киренского СО РАН

Академгородок, 50/38, Красноярск, 660036

Россия

Сергей И. Бурков

Владимир И. Турчин

Сергей В. Юркевич

Павел О. Суходаев

Ирина С. Райкова

Институт инженерной физики и радиоэлектроники

Сибирский федеральный университет

Свободный, 79, Красноярск, 660041

Россия

Эхо-импульсным ультразвуковым методом измерены скорости объемных акустических волн в базовых и повернутых срезах и рассчитаны значения $C_{i j k l}^{E}$ u $e_{i j k}$ в монокристаллах $Y_{1} l_{3}\left(B O_{3}\right)_{4}$. Величинь пвезомодулей $d_{i j k}$ этих монокристаллов определены квазистатическими измерениями, диэлектрических постоянных $\varepsilon_{i j}^{\sigma}$ - методом плоского конденсатора. Экспериментальные значения материальных постоянных применены для исследования анизотропии характеристик акустических волн в монокристаллах $\mathrm{YAl}_{3}\left(\mathrm{BO}_{3}\right)_{4}$.

Ключевые слова: электромеханические свойства, акустические волны, мулътиферроики. 